\title{
Competing for Capital When Labor is Heterogeneous
}

Y. Sato and J. F. Thisse

Discussion Paper 2005-45

\section{Département des Sciences Économiques de l'Université catholique de Louvain}




\title{
Competing for capital when labor is heterogeneous*
}

\author{
Yasuhiro Sato ${ }^{\dagger}$ and Jacques François Thisse ${ }^{\ddagger}$
}

September 5, 2005

\begin{abstract}
This paper investigates the impacts of capital mobility and tax competition in a setting with imperfect matching between firms and workers. The small country always gains and the large country always loses from tax competition, thus implying tax competition leads to redistribution from the large to the small country. However, the large country always attains a higher utility than does the small country. These results imply that our model encapsulates both the "importance of being small" as well as the "importance of being large". We also show that tax harmonization leads to redistribution from the large to the small country.
\end{abstract}

Keywords: fiscal competition, local labor markets, capital mobility

JEL Classification: F21, H32, J31

${ }^{*}$ We thank Kristian Behrens, Gilles Duranton, Jonathan Hamilton, Gianmarco I. P. Ottaviano, Susana Peralta, Frederic Robert-Nicoud, Hylke Vandenbussche, Tanguy van Ypersele, and the participants of the CEPR Conference "Agglomeration economies and regional growth" (May 2005) for very useful comments and discussions. Of course, all remaining errors are our own.

${ }^{\dagger}$ Graduate School of Environmental Studies, Nagoya University (Japan) and CORE, Université catholique de Louvain (Belgium).

${ }^{\ddagger}$ CORE, Université catholique de Louvain (Belgium), PSE (France) and CEPR. 


\section{Introduction}

During the last two decades, OECD countries have experienced very high increases in foreign direct investments (FDI). Reporting the trends of FDI inflows and outflows as percentage of GDP across OECD countries from 1981 to 1999, Miyake and Sass (2000) find that both were around 0.5 percent in 1981 and rose to 2.5 percent in 1999. This internationalization of production has increased the real inward FDI position of the average OECD country, measured in constant 1996 purchasing power parities, from $\$ 81$ billion to $\$ 158$ billion over the 1990-2000 period (OECD, 2003). In such a context, the existence of differentials in corporate tax rates is likely to affect the location of economic activity, whereas empirical evidence confirms that governments vastly use this instrument to influence firms' locational choices (Mooij and Ederveen, 2003). Building on that observation, the literature on fiscal competition aims at studying how governments choose their tax rates in a strategic environment, typically by assuming that the productivity of capital is expressed through a standard neoclassical production function (Wilson, 1999).

Because the outcome of fiscal competition crucially depends on the spatial mobility of production factors, a relevant approach is to build on the microeconomic underpinnings that explain the location of firms and, thus, the international distribution of capital. This is what new economic geography (NEG) has accomplished by explaining how firms do interact to form clusters within a few regions (Fujita et al., 1999; Baldwin et al., 2003). It seems, therefore, natural to revisit the process of fiscal competition by incorporating the main forces uncovered by NEG, namely increasing returns, market size, and imperfect competition. This is the road taken recently by Anderson and Forslid (2003), Baldwin and Krugman (2004), and Ottaviano and van Ypersele (2005). However, very much like in NEG, all these authors have chosen to stress the role of the product market. Yet, recent empirical contributions suggest that labor market pooling is one of the main reasons that explain the existence of firms' clusters (Dumais et al., 2002; Rosenthal and Strange, 2004). The specificity of human capital being itself the main reason for imperfect matching between firms and workers, we find it appealing to study how skill mismatch affects the spatial distribution of firms through both firms' locational choices and the working of local labor markets (Kim, 1989; Hamilton et al., 2000; Amiti and Pissarides, 2005). When the labor force is heterogeneous in the skill space, firms are able to set wages below the marginal productivity of labor by differentiating technologies. As a consequence, firms operate on imperfectly competitive labor markets. Note, also, that skill mismatch yields increasing returns with respect to the size of labor pool, thus implying that our approach concurs with NEG (Kim, 1989; Helsley and Strange, 1990).

Assuming that capital markets are perfect and integrated whereas labor markets are imperfect and local, we study how fiscal competition affects firms' distribution and consumers' welfare across countries of different sizes. Because our main focus is on the impact of fiscal competition on the location of firms, we disregard the possible inefficiency of public goods provision and assume that national governments tax capital to make their residents better off. As most FDI takes place in countries with similar technologies and factor endowments (think of the OECD countries), we also abstract from comparative advantage of both the Ricardian and Heckscher-Ohlin types. However, although the standard model of fiscal competition assumes that competing jurisdictions have the same size, countries involved in FDI vastly differ in terms of market sizes. ${ }^{1}$ Size being out of the reach of harmonization, we thus choose to focus on a setting in which countries are asymmetric in the size of their capital and labor endowments.

Our main results may be summarized as follows. First, although most fiscal competition

\footnotetext{
${ }^{1}$ For a general description of asymmetries in standard models of fiscal competition, see Peralta and van Ypersele (2005).
} 
models are plagued by the nonexistence of a Nash equilibrium, we prove that our tax game has a unique Nash equilibrium. This in turn allows us to compare the fiscal competition outcome to both the autarchy and no-tax cases. In all configurations, we show that the large country's residents enjoy a higher utility level than do those of the small country, thus implying the "importance of being large". ${ }^{2}$ Though the large country has more firms than does the small one, competition on local labor markets hinders the large country to have a more than proportionate share of firms. Furthermore, the few existing studies on asymmetric tax competition predict that the large country has higher corporate tax rate than does the small one (Bucovetsky, 1991; Wilson, 1991; Haufler and Wooton, 1999; Ottaviano and van Ypersele, 2005). This prediction does not fit well the real world, however. For example, Devereux et al. (2002) report the effective corporate tax rates with respect to several OECD countries. Their Figure 7 reveals that, if the effective average tax rates in Germany, Japan, and the United States are higher than those set in Austria, Finland and Sweden, those prevailing in Belgium and in Greece are higher than those in France and in the United Kingdom. We show that the small country levies higher corporate tax rate than does the large country. Hence, by focussing on microeconomic underpinnings of firms' location, we are able to identify results that invite us to reconsider the impact of fiscal competition.

Finally, our analysis has three major redistributional implications. The first one confirms the existing literature by showing that tax competition distorts the allocation of capital by leading to redistribution between countries. The next implication is that the small country always gains and the large country always loses from tax competition, thus implying tax competition leads to redistribution from the large to the small country. This is due to the fact that the small country is able to tax its domestic capital but some foreign capital too. However, the large country always reaches a higher utility level than does the small country. This sharply differs from the result obtained in the existing studies where the small country typically attains higher utility under tax competition (Bucovetsky, 1991; Wilson, 1991). Together, these results mean that our model encapsulates the "importance of being small" as well as the "importance of being large". The final implication is that tax harmonization does not cause any distortion in the sense that net global output is maximized, but leads to redistribution from the large to the small country.

The remaining of the paper is organized as follows. The model is presented in section 2 . In section 3, we study the international distribution of capital in the no-tax case, whereas the process of fiscal competition is discussed in section 4 . Section 5 concludes by discussing extensions and policy implications.

\section{The model and preliminary results}

Consider an economy formed by two countries, labeled 1 and 2, and a total mass $L$ of consumers. Each consumer is endowed with one unit of labor and one unit of capital. Our modeling strategy thus abstracts from redistributional issues between capital-owners and workers. Let $\theta \in(0,1)$ denote the share of consumers in country 1 , which implies that $\theta$ also measures that country's shares of labor and capital. Let $l_{1}=\theta L$ and $l_{2}=(1-\theta) L$ denote the mass of consumers in countries 1 and 2 , respectively. Without loss of generality, we assume that $l_{1} \geq l_{2}$. Throughout this paper, we refer to $\theta$ and to $(1-\theta)$ as being the size of countries 1 and 2. Unless explicitly mentioned, we consider here asymmetric countries with $\theta>1 / 2$, thus implying that country 1 (2) is the large (small) country. Consumers are immobile and can supply labor only in the country in which they reside, so that labor markets are local. By contrast, consumers are free to supply capital wherever they want.

\footnotetext{
${ }^{2}$ This is reminiscent of Ottaviano and van Ypersele (2005) who assume that countries have different productmarket sizes.
} 


\section{$2.1 \quad$ Local labor markets}

The industry is formed by firms that supply a homogeneous good sold in each country on a competitive market. This good can be shipped at zero cost between the two countries so that its price is the same on both markets; we take it as the numéraire. Hence, product market conditions do not influence firms' locational choices. It is worth stressing that introducing positive trade costs for the final good does not change our main results when these costs are sufficiently low. ${ }^{3} \mathrm{~A}$ firm is fully described by the amount of capital it uses as well as by the type of worker it needs. Let $f>0$ be the fixed requirement of capital needed to be active on the market, so that the total number of firms in the economy is given by $N=L / f$. Each firm has a specific technology such that workers can produce only when they perfectly match the firm's skill needs. Workers have the same level of general human capital but heterogeneous skills. Since workers are heterogeneous, they have different matches with a firm's job offer. Thus, if firm $k$ hires a worker whose skill differs from $x_{k}$, the worker must get trained and her cost of training to meet the firm's skill requirement is a function of the difference between the worker's skill $x$ and the firm $k$ 's skill requirement $x_{k}$.

Workers are heterogeneous in the type of work they are best suited for, but there is no ranking in any sense of these types of work. Workers' skill types are denoted by $x$. The characteristics of a worker relevant to firms are summarized by her skill. In describing the heterogeneity of workers, we follow Kim (1989) and Hamilton et al. (2000), among others, by assuming that the skill space is described by the circumference $C$ of a circle with a length normalized to one. Individuals' skills are continuously and uniformly distributed along this circumference; the density is constant in country $i$ and denoted by $l_{i}$. In this context, the density expresses the size of the local labor market. There are $n_{i}$ firms in country $i$, with $n_{1}+n_{2}=N$. Firms' job requirements $x_{k}$ are equally spaced along the circumference $C$ so that $1 / n_{i}$ is the distance between two adjacent firms in the skill space. ${ }^{4}$ The training cost function is $\beta\left|x-x_{k}\right|$, where $\beta$ expresses the ability of a worker to learn how to adjust to a technology different from her skill. After training, all workers are identical from the firm's viewpoint since their ex post productivity is observable and equal to 1 by convention (thus, there is no moral hazard problem within firms).

In this paper, we assume that each worker's skill type is not observable for firms and firms know only the distribution of $x$ (Hamilton et al., 2000). Hence, the training costs are paid by workers. However, workers know their own types and observe the firms' skill needs. In order to induce the appropriate set of workers to take jobs with the most suitable firm, workers must pay at least some part of the training cost. In addition, since the supply of a worker is inelastic, firms cannot offer a wage menu so that the worker must pay for all the costs of training, which are not observable to the firm (hence resolving the adverse selection problem). Consequently, each firm $i$ offers the same wage to all its workers, conditional on the worker having been trained to the skill $x_{k}$. Each worker then compares the wage offers of firms and the required training costs; she simply chooses to work for the firm offering the highest wage net of training costs.

Suppose that firm $k$ is located in country $i$. Assuming that the skill spaces are identical across countries, firms on each side of $k$ offer wages $w_{i, k-1}$ and $w_{i, k+1}$, then firm $k$ 's labor pool consists of two subsegments whose outer boundaries are $\bar{x}_{i, k}$ and $\bar{x}_{i, k+1}$. The worker at $\bar{x}_{i, k}$ receives the same net wage from firm $k$ and firm $k-1$, whereas the worker at $\bar{x}_{i, k+1}$ receives the same net wage from firm $k$ and firm $k+1$. Because firm $k$ knows the training cost function and all firms' skill requirements, it can determine $\bar{x}_{i, k}$ and $\bar{x}_{i, k+1}$ as the solutions to the two equations $w_{i, k}-$ $\beta\left|x_{i, k}-\bar{x}_{i, k}\right|=w_{i, k-1}-\beta\left|\bar{x}_{i, k}-x_{i, k-1}\right|$ and $w_{i, k}-\beta\left|\bar{x}_{i, k+1}-x_{i, k}\right|=w_{i, k+1}-\beta\left|x_{i, k+1}-\bar{x}_{i, k+1}\right|$.

\footnotetext{
${ }^{3}$ This is because the inequalities shown below remain true.

${ }^{4}$ By analogy with what has been shown on a differentiated product market, the equidistant configuration of technologies is likely to be an equilibrium outcome of a game in which firms would choose their technologies prior to their wages.
} 
Hence, we have

$$
\begin{aligned}
\bar{x}_{i, k} & =\frac{w_{i, k-1}-w_{i, k}+\beta\left(x_{i, k}+x_{i, k-1}\right)}{2 \beta} \\
\bar{x}_{i, k+1} & =\frac{w_{i, k}-w_{i, k+1}+\beta\left(x_{i, k}+x_{i, k+1}\right)}{2 \beta} .
\end{aligned}
$$

Firm $k$ 's profits are then given by

$$
\begin{aligned}
\pi_{i, k} & =\int_{\bar{x}_{i, k}}^{\bar{x}_{i, k+1}} l_{i}\left(1-w_{i, k}\right) d x-r_{i} f \\
& =l_{i}\left(1-w_{i, k}\right)\left(\bar{x}_{i, k+1}-\bar{x}_{i, k}\right)-r_{i} f
\end{aligned}
$$

where $r_{i}$ is the price of capital and $w_{i, k}$ the wage firm $k$ pays when it is located in country $i$. Note that countries have different wages because labor is immobile between countries. In the rest of this section, we suppose that capital is immobile. Hence, the number of firms in each country is given and each country is in autarky. The amount of capital available in country $i$ being $l_{i}$, the fact that a firm needs $f$ units of capital to be active implies that the number of firms in country $i$ under autarky is given by

$$
n_{i}^{a}=\frac{l_{i}}{f}
$$

where the superscript $a$ stands for the autarky case. This in turn implies that the large country has a larger number of firms than does the small $\left(n_{1}^{a}>n_{2}^{a}\right)$. However, the capital-labor ratio is the same across countries

$$
\frac{n_{1}^{a}}{l_{1}}=\frac{n_{2}^{a}}{l_{2}}
$$

because the per capita endowment of capital is the same in the two countries.

\subsection{Equilibrium factor prices}

We now determine the equilibrium values of $w_{i, k}$ and $r_{i}$. We find the equilibrium wages by taking the first-order condition for $\pi_{i, k}$ with respect to $w_{i, k}$ :

$$
\frac{\partial \pi_{i, k}}{\partial w_{i, k}}=-l_{i}\left(\bar{x}_{i, k+1}-\bar{x}_{i, k}\right)+l_{i}\left(1-w_{i, k}\right)\left(\frac{\partial \bar{x}_{i, k+1}}{\partial w_{i, k}}-\frac{\partial \bar{x}_{i, k}}{\partial w_{i, k}}\right)=0 .
$$

Focusing on a symmetric equilibrium, it follows from (1), (5), and $\bar{x}_{i, k+1}-\bar{x}_{i, k}=1 / n_{i}$ that

$$
w_{i, k}^{*}=1-\frac{\beta}{n_{i}} \equiv w_{i}^{*}
$$

Thus, the equilibrium wage is equal to the marginal productivity of labor after training, minus a premium that local firms are able to levy because workers cannot move costlessly from one firm to another. Note that this premium decreases as the number of firms located in this country rises because they have less market power.

Substituting $w_{i, k}^{*}$ into (2), we get

$$
\pi_{i, k}^{*}=\frac{\beta l_{i}}{n_{i}^{2}}-r_{i} f .
$$


Note that output per capita in country $i$ is given by

$$
\begin{aligned}
& \left\{\int_{\bar{x}_{i, k}}^{x_{i, k}} l_{i}\left[1-\beta\left(x_{i, k}-x\right)\right] d x+\int_{x_{i, k}}^{\bar{x}_{i, k+1}} l_{i}\left[1-\beta\left(x-x_{i, k}\right)\right] d x\right\} \\
& \times\left(\int_{\bar{x}_{i, k}}^{\bar{x}_{i, k+1}} l_{i} d x\right)^{-1}=1-\frac{\beta}{4 n_{i}}
\end{aligned}
$$

thus implying the existence of increasing returns with respect to country size.

Expression (7) encapsulates the main forces at work in the present setting. First, when its size increases, a country becomes more profitable to firms because a larger labor pool allows them to hire more workers with a better match and, hence, to produce and sell more. We refer to that as the labor-market pooling effect. Second, when the number of firms $n_{i}$ rises, there is more competition on the labor market, the size of which is fixed because workers are geographically immobile. This leads firms to pay higher wages, thus making country $i$ less attractive. We call this force the labor-market crowding effect.

It remains to describe how the price of capital is determined in each country. Following a well-established tradition in this strand of literature, we assume that there is free entry in the industry. Consequently, competition for capital drives profits down to zero, thus implying that $r_{i}$ must be such that $\pi_{i, k}^{*}=0$. This yields the equilibrium price of capital in country $i$ :

$$
r_{i}^{*}=\frac{\beta l_{i}}{f n_{i}^{2}}
$$

Then, the price of capital in autarky is

$$
r_{i}^{a}=\frac{\beta}{n_{i}^{a}}
$$

Hence, in autarky the price of capital is larger in the small country than in the large one.

The (indirect) utility of an individual of skill type $x$ working for firm $k$ in country $i$ is given by

$$
V_{i, k}(x)=w_{i}^{*}-\beta\left|x-x_{i, k}\right|+r_{i}^{*}
$$

which is equal to

$$
V_{i, k}(x)=1-\frac{\beta}{n_{i}}-\beta\left|x-x_{i, k}\right|+\frac{\beta l_{i}}{f n_{i}^{2}} .
$$

The average utility of firm $k$ 's employees is then

$$
\begin{aligned}
V_{i, k}= & \left\{\int_{\bar{x}_{i, k}}^{x_{i, k}} l_{i}\left[1-\frac{\beta}{n_{i}}-\beta\left(x_{i, k}-x\right)+r_{i}^{*}\right] d x\right. \\
& \left.+\int_{x_{i, k}}^{\bar{x}_{i, k+1}} l_{i}\left[1-\frac{\beta}{n_{i}}-\beta\left(x-x_{i, k}\right)+r_{i}^{*}\right] d x\right\} \\
& \times\left(\int_{\bar{x}_{i, k}}^{\bar{x}_{i, k+1}} l_{i} d x\right)^{-1} .
\end{aligned}
$$

Because $\bar{x}_{i, k+1}=x_{i, k}+1 / 2 n_{i}$ and $\bar{x}_{i, k}=x_{i, k}-1 / 2 n_{i}$ at the symmetric equilibrium, we have

$$
V_{i, k}=1-\frac{5 \beta}{4 n_{i}}+r_{i}^{*} \equiv V_{i}
$$

In this expression, the second term represents the effect of improving the quality match. When the number of local firms rises, the average mismatch decreases, implying that the equilibrium 
wage increases. However, as shown by (7), an increase in the number of firms also leads to a lower capital price. Thus, the total impact of the number of firms on welfare is a priori ambiguous. From (3), (9) and (10), we have

$$
\begin{aligned}
V_{1}^{a}-V_{2}^{a} & =\frac{5 \beta}{4}\left(\frac{1}{n_{2}^{a}}-\frac{1}{n_{1}^{a}}\right)+\frac{\beta}{f}\left[\frac{l_{1}}{\left(n_{1}^{a}\right)^{2}}-\frac{l_{2}}{\left(n_{2}^{a}\right)^{2}}\right] \\
& =\frac{\beta}{4}\left(\frac{1}{n_{2}^{a}}-\frac{1}{n_{1}^{a}}\right)=\frac{\beta f(2 \theta-1)}{4 L \theta(1-\theta)}>0 \\
\frac{d\left(V_{1}^{a}-V_{2}^{a}\right)}{d \theta} & >0 .
\end{aligned}
$$

Hence, increasing the share of country 1 in the global economy makes the residents of this country relatively better off than those of the small country's residents. The welfare gap between the two countries thus rises. Moreover, the difference in welfare is a reflection of the presence of increasing returns in each country since

$$
\frac{d^{2}\left(V_{1}^{a}-V_{2}^{a}\right)}{d \theta^{2}}>0
$$

Summarizing the foregoing discussion, we have:

Proposition 1 Consider two countries that have different sizes but the same relative endowment of capital and labor. When capital is immobile, consumers reach a higher utility level in the large country. Furthermore, the larger the difference in size, the larger the gap in individual welfare levels between the two countries.

\section{Capital mobility}

In this section, we allow for capital mobility so that the number of firms located in a country is no longer tied to the amount of local capital. In this process, the labor-market pooling effect has the nature of an attraction force, whereas the labor-market crowding effect acts as a repulsion force. The international allocation of capital is thus the outcome of two opposite forces. Throughout the rest of the paper, we assume that the number of firms is sufficiently large to avoid the integer problem and treat $n_{i}$ as a real number.

\subsection{Free market outcome}

When capital is mobile between countries, capital flows to the country with higher capital price. Hence, arbitrage induces the capital prices in both countries to be the same:

$$
r_{1}^{*}=r_{2}^{*}
$$

Using (8), this equilibrium condition can be rewritten as follows:

$$
\frac{l_{1}}{n_{1}^{2}}=\frac{l_{2}}{n_{2}^{2}}
$$

so that $n_{1}^{*}>n_{2}^{*}$ if and only if $l_{1}>l_{2}$, whereas $l_{1}=l_{2}$ implies that $n_{1}^{*}=n_{2}^{*}$.

Since the amount of capital in the global economy is fixed, the total number of firms is still given by $N$. Because $n_{1}+n_{2}=N$, (11) allows us to determine the equilibrium number of firms in country $i$ :

$$
n_{i}^{m}=\frac{\sqrt{l_{i}}}{\sqrt{l_{1}}+\sqrt{l_{2}}} N
$$


where the superscript $m$ stands for the case of mobile capital. Using $l_{1}=\theta L$ and $l_{2}=(1-\theta) L$, the corresponding value of the price of capital is then obtained by substituting (12) into (8):

$$
r^{m}=\frac{\beta}{N}(\sqrt{\theta}+\sqrt{1-\theta})^{2}
$$

which is a decreasing and concave function of $\theta$ over the interval $(1 / 2,1)$.

When the two countries have different sizes, the mobility of capital generates a distribution of firms that differs from the one arising under autarky. Comparing (3) and (12), it is readily verified that

$$
n_{1}^{m}<n_{1}^{a} \quad n_{2}^{m}>n_{2}^{a} .
$$

Thus, capital is exported from the large country to the small country. This should not come as a surprise as, under autarky, the price of capital is higher in the latter than in the former. Yet, the large country still retains a larger number of firms than the small one: $n_{1}^{m}>n_{2}^{m}$. Indeed, (7) and the equalization of profits between countries implies that the labor-market pooling effect generated by the large country must be exactly offset by a stronger labor-market crowding effect. This, in turn, means that the large country hosts a larger number of firms.

This is not the end of the story, however. Indeed, it is easy to see that the number of firms per capita is smaller in the large country than in the small country:

$$
\frac{n_{1}^{m}}{l_{1}}<\frac{n_{2}^{m}}{l_{2}} .
$$

Using (4) and (13), we may then conclude that

$$
\frac{n_{1}^{m}}{l_{1}}<\frac{n_{1}^{a}}{l_{1}}=\frac{n_{2}^{a}}{l_{2}}<\frac{n_{2}^{m}}{l_{2}} .
$$

Hence, when capital is mobile, the large economy accommodates more firms than the small one, but it does so less than proportionally. This is because country 1 has a larger labor pool that allows it to attract more firms, which pay higher wages. In the process of international capital allocation, the negative labor-market crowding effect partly offsets the positive labor-market pooling effect and leads to a more dispersed distribution of capital than in autarky.

Having said that, we now want to know whether our setting exhibits a "home market effect". According to Krugman (1980), when the industry is characterized by increasing returns to scale, the large country would attract a more than proportionate share of firms. Define the share of firms in country 1 as $\lambda=n_{1} / N$. It then follows immediately from (12) that

$$
\lambda^{m}=\frac{\sqrt{\theta}}{\sqrt{\theta}+\sqrt{1-\theta}} .
$$

Accordingly, we have

$$
\lambda^{m}=\frac{\sqrt{\theta}}{\sqrt{\theta}+\sqrt{1-\theta}}<\frac{\theta}{\theta+\sqrt{1-\theta} \sqrt{1-\theta}}=\theta
$$

because $\theta>1-\theta$, where the equality holds if and only if $\theta=1 / 2$. Thus, unless the two countries have the same size, the large country hosts a less than proportional share of the industry, implying the existence of a reverse home market effect. ${ }^{5}$ As shown by (11), this is because the labor-market

\footnotetext{
${ }^{5}$ Behrens (2005) presented another possible story that generates a reverse home market effect. He considered a model having both traded and non-traded goods, and showed that non-traded goods industries may exhibit a reverse home market effect.
} 
pooling effect is proportional to the number of firms whereas the labor-market crowding effect is proportional to the square of the number of firms, thus making the large country relatively less attractive to firms. Consequently, even though more firms locate in country 1 than in country 2 , country 1's share of firms is smaller than its consumption share.

The above arguments can be summarized as follows.

Proposition 2 Consider two countries that have different sizes but the same relative endowment of capital and labor. When capital is mobile, the large country has more capital but the small country imports capital. Furthermore, capital mobility gives rise to a reverse home market effect.

As one country imports capital, countries face different incentives to tax capital. We will see in section 4 how this is reflected in the tax outcome.

\subsection{The welfare implications of capital mobility}

The equilibrium distribution of firms minimizes total training costs in the global economy. Indeed, total training costs are given by

$$
\begin{aligned}
T\left(n_{1}, n_{2}\right) & =2 n_{1} \int_{0}^{1 /\left(2 n_{1}\right)} l_{1} \beta \sigma d \sigma+2 n_{2} \int_{0}^{1 /\left(2 n_{2}\right)} l_{2} \beta \sigma d \sigma \\
& =\frac{\beta l_{1}}{4 n_{1}}+\frac{\beta l_{2}}{4 n_{2}} .
\end{aligned}
$$

The first order condition for the minimization of $T$ with respect to $n_{1}$ and $n_{2}$, taking $n_{1}+n_{2}=N$ into account, yields (11). Note that the net output of the global economy is $L-T\left(n_{1}, n_{2}\right)$. Hence, the equilibrium distribution of firms maximizes the net output of the global economy. Thus, despite imperfect competition on local labor markets, the international allocation of capital is globally efficient under free mobility. However, it generates redistributive effects between the two countries.

To see them, we compare the welfare levels reached in each country at the market outcome with and without capital mobility. From $r_{1}=r_{2}$ and (12), the utility difference across countries in the mobile capital case is given by

$$
V_{1}^{m}-V_{2}^{m}=\frac{5 \beta}{4}\left(\frac{1}{n_{2}^{m}}-\frac{1}{n_{1}^{m}}\right)=\frac{5 \beta f(2 \theta-1)}{4 L \sqrt{\theta} \sqrt{1-\theta}}>0
$$

because $\theta>1 / 2\left(\right.$ and $\left.n_{1}^{m}>n_{2}^{m}\right)$. Furthermore, the welfare gap rises as the size discrepancy increases.

Turning to comparisons of welfare under mobility and autarky, standard calculations show that

$$
\begin{aligned}
V_{i}^{m}-V_{i}^{a} & =\left(\frac{1}{n_{i}^{a}}-\frac{1}{n_{i}^{m}}\right)\left[\frac{5 \beta}{4}-\frac{\beta l_{i}}{f}\left(\frac{1}{n_{i}^{m}}+\frac{1}{n_{i}^{a}}\right)\right] \\
& =\frac{\beta f\left(l_{j}-\sqrt{l_{i}} \sqrt{l_{j}}\right)\left(l_{j}-3 l_{i}-4 \sqrt{l_{i}} \sqrt{l_{j}}\right)}{4\left(l_{1}+l_{2}\right)^{2} l_{i}} .
\end{aligned}
$$

As $\theta>1 / 2$ and, hence, $l_{1}>l_{2}$, this implies that

$$
V_{1}^{m}-V_{1}^{a}>0 .
$$

Hence, the large country always gains from capital mobility. Though intuitive, this result is not immediate. Indeed, country 1's residents get higher capital incomes because its price rises when it can be invested abroad, but they earn lower wages because the number of local firms is lower. 
The implications of capital mobility for the small country are even less straightforward. Because $l_{1}-\sqrt{l_{1}} \sqrt{l_{2}}>0$, it turns out that $V_{2}^{m}-V_{2}^{a}>0$ holds if and only if

$$
l_{1}-3 l_{2}-4 \sqrt{l_{1}} \sqrt{l_{2}}=(4 \theta-3-4 \sqrt{\theta} \sqrt{1-\theta}) L>0 .
$$

This is a second degree inequality that is satisfied on the unit interval if and only if $\theta>\theta_{c} \equiv$ $(5+\sqrt{7}) / 8>1 / 2$. Thus, we have:

Proposition 3 Compared to the autarky case, capital mobility always raises the utility level in the large country. However, the utility level in the small country increases if and only if countries have very different sizes.

When capital is mobile, the global output net of training costs increases and reaches its maximum at the equilibrium distribution of firms. However, these gains need not benefit each country. When capital is mobile, some firms move to the small country. Hence, the large country's capital income rises but its labor income falls, whereas these two effects go in the opposite direction in the small country. On the one hand, in the large country, the gains resulting from the higher price of capital for country 1's residents always more than compensate their wage decrease. This is because country 1 hosts more firms than country 2, thus making the marginal and negative impact of the labor-market crowding effect weak enough, whereas the marginal and positive impact of the capital price remains strong enough. On the other hand, consumers in country 2 earn higher wages under capital mobility than under autarky (see Figure 1). Whether these gains are large enough to compensate for the lower price of capital now depends on the relative size of the two countries. As the large country gets bigger, the wage level in the small country goes down, but its decrease is sharper under autarky than under capital mobility. Consequently, when $\theta$ is sufficiently large, the gains in wage income may compensate the loss in capital income. By contrast, when country sizes are similar, such a compensation is not possible. This shows that country size matters for the welfare implications of capital mobility, in which case capital mobility does not necessarily reduce international inequalities.

\section{Capital taxation}

\subsection{The tax game}

This section considers two local governments that tax local firms and redistribute the proceeds to their residents as lump-sum transfers. Let $s_{i}$ and $t_{i}$ denote the lump-sum transfer to consumers and the lump-sum tax on firms in country $i{ }^{6}$ Note that the former may be positive $\left(s_{i}>0\right)$ and the latter negative $\left(t_{i}<0\right)$, thus meaning that government $i$ may decide to subsidize firms and, therefore, to tax its residents instead of taxing capital.

In this case, the profit of a firm (7) and the utility level of a worker (10) become:

$$
\begin{aligned}
\pi_{i, k}^{*} & =\frac{\beta l_{i}}{n_{i}^{2}}-r_{i} f-t_{i} \\
V_{i} & =1-\frac{5 \beta}{4 n_{i}}+r_{i}+s_{i} .
\end{aligned}
$$

In what follows, we consider a standard two stage game in which local governments, first, determine $s_{i}$ and $t_{i}$ simultaneously and, then, firms enter the market, decide where to locate and pay the

\footnotetext{
${ }^{6}$ Because firms would not operate under negative profits, the nonegativity of profits is here a natural constraint to satisfy. It yields an upper bound on $t_{i}$, which is itself bounded above by the highest possible output of country $i$, that is, $\alpha l_{i}$.
} 
corresponding wage. From now on, we will refer to the first stage game as the tax game. The equilibrium concept we adopt is a subgame perfect Nash equilibrium. As usual, the model is solved by backward induction.

Consider the second stage subgame induced by $s_{i}$ and $t_{i}(i=1,2)$. The capital price in each country is then given by

$$
r_{i}=\frac{1}{f}\left(\frac{\beta l_{i}}{n_{i}^{2}}-t_{i}\right) .
$$

Free entry and the equalization of capital prices then lead to the condition:

$$
\frac{\beta l_{1}}{n_{1}^{2}}-t_{1}=\frac{\beta l_{2}}{n_{2}^{2}}-t_{2}
$$

Hence, firms' decisions in the second stage imposes a constraint, given by (17), on the tax game between countries 1 and 2 .

We now consider the tax game. Country $i$ 's government, which fully anticipates the influence of its decision on the resulting distribution of firms determined by (17), maximizes (15) with respect to $s_{i}$ and $t_{i}$ under the budget constraint

$$
s_{i} l_{i}=t_{i} n_{i}
$$

Substituting (16) and $s_{i} l_{i}=t_{i} n_{i}$ into (15), we obtain

$$
V_{i}=1-\frac{5 \beta}{4 n_{i}}+\frac{1}{f}\left(\frac{\beta l_{i}}{n_{i}^{2}}-t_{i}\right)+\frac{n_{i} t_{i}}{l_{i}} .
$$

Substituting $n_{j}=N-n_{i}$ into (17), we get

$$
\frac{\beta l_{i}}{n_{i}^{2}}-t_{i}=\frac{\beta l_{j}}{\left(N-n_{i}\right)^{2}}-t_{j}
$$

Thus, the welfare problem of government $i$ is modeled as a game in which this government maximizes (18) with respect to $t_{i}$, subject to the constraint (19).

We have just seen that, at any equilibrium of the tax game, the following condition must be satisfied:

$$
g\left(t_{i}, n_{i} ; t_{j}\right) \equiv \frac{\beta l_{i}}{n_{i}^{2}}-t_{i}-\frac{\beta l_{j}}{\left(N-n_{i}\right)^{2}}+t_{j}=0 .
$$

Totally differentiating $g\left(t_{i}, n_{i} ; t_{j}\right)$ for a given $t_{j}$ yields $d n_{i} / d t_{i}$. Taking the total differential of $V_{i}$ and using $d n_{i} / d t_{i}$ then leads to

$$
t_{i}^{*}=\frac{3 \beta l_{i}}{4 n_{i}^{2}}+\frac{2 \beta l_{i} l_{j}}{n_{j}^{3}}\left(\frac{n_{i}}{l_{i}}-\frac{1}{f}\right)
$$

A similar argument holds for country $j \neq i$. From $n_{1}+n_{2}=N=\left(l_{1}+l_{2}\right) / f$, it follows that

$$
\frac{l_{i}}{f}-n_{i}=n_{j}-\frac{l_{j}}{f}
$$

Substituting (20) into (19), rearranging terms, and using (21), we see that (19) may be rewritten as follows:

$$
\frac{1}{l_{1}}\left(\frac{l_{1}}{n_{1}}\right)^{2}\left(\frac{7}{8}-\frac{l_{1}}{f n_{1}}\right)=\frac{1}{l_{2}}\left(\frac{l_{2}}{n_{2}}\right)^{2}\left(\frac{7}{8}-\frac{l_{2}}{f n_{2}}\right) .
$$


Thus, if a Nash equilibrium of the tax game exists, there is a pair $\left(t_{1}^{*}, t_{2}^{*}\right)$ such that (i) $t_{i}^{*}$ maximizes $V_{i}\left(t_{i}, t_{j}^{*}\right), i, j=1,2$ and $j \neq i$ and (ii) at the resulting distribution of firms, both the conditions $n_{1}^{*}+n_{2}^{*}=N$ and $(22)$ are satisfied.

The existence of a (pure-strategy) Nash equilibrium in tax games is known to be a very problematic issue. Even in the case of simple games such as those by Wilson (1986) and Zodrow and Mieszkowski (1986), the existence of a Nash equilibrium has so far been proven only under special circumstances. Yet, the following result is shown in Appendix A.

Proposition 4 The tax game has a unique Nash equilibrium.

Regarding the equilibrium distribution of firms, the following result is shown to hold in Appendix B.

Proposition 5 The equilibrium number of firms per capita is larger in the small country than in the large country. However, the large (small) country has more (less) firms per capita at the tax-game outcome than at the no-tax outcome.

This proposition implies that

$$
\frac{n_{1}^{m}}{l_{1}}<\frac{n_{1}^{g}}{l_{1}}<\frac{n_{2}^{g}}{l_{2}}<\frac{n_{2}^{m}}{l_{2}}
$$

where the superscript $g$ represents the capital mobile case with active local governments. Since $n_{1}+n_{2}=N$ can be rewritten as

$$
l_{1}\left(\frac{n_{1}}{l_{1}}-\frac{1}{f}\right)=l_{2}\left(\frac{1}{f}-\frac{n_{2}}{l_{2}}\right)
$$

(23) implies that

$$
\frac{n_{1}^{g}}{l_{1}}<\frac{1}{f}<\frac{n_{2}^{g}}{l_{2}}
$$

Combining (17) with (20), we obtain

$$
t_{2}^{*}>0
$$

because $\theta>1 / 2$. Moreover, from (23), it follows that $7 / 8-l_{1} /\left(f n_{1}^{g}\right)>7 / 8-l_{2} /\left(f n_{2}^{g}\right)$. This and (22) thus yields

$$
\frac{l_{2}}{\left(n_{2}^{g}\right)^{2}}>\frac{l_{1}}{\left(n_{1}^{g}\right)^{2}}
$$

Thus, (17) implies that

$$
t_{1}^{*}-t_{2}^{*}=\beta\left[\frac{l_{1}}{\left(n_{1}^{g}\right)^{2}}-\frac{l_{2}}{\left(n_{2}^{g}\right)^{2}}\right]<0 .
$$

We may summarize our results as follows.

Proposition 6 At the tax-game outcome, the government of the small country always taxes firms. However, the government of the large country either subsidies or taxes firms. When it taxes firms, its tax level is always lower than the one chosen by the government of the small country.

Because the taxes set by local governments distort the international distribution of capital, the total output is lower under tax competition. Hence, from the global point of view, tax competition induces a wasteful redistribution of capital from the small to the large country. Furthermore, the fact that the small country imports capital allows it to be more aggressive than the large country in its tax policy. 
The results in the foregoing proposition are to be contrasted to those obtained in models with imperfect competition in the product market (Haufler and Wooton, 1999; Ottaviano and van Ypersele, 2005). Haufler and Wooton (1999) considered two countries aiming at attracting a foreign owned monopoly, whereas Ottaviano and van Ypersele (2005) assumed two countries competing for monopolistic competitive firms. In both cases, the large country appears to be more attractive to firms than a small country. Accordingly, the small country offers a lower tax rate than does the large country in order to counterbalance the comparative advantage of the large country. In our model, the labor-market pooling effect makes the large country more attractive for firms than the small country, but the labor-market crowding effect makes the large country less attractive than the small country. Because the latter effect dominates the former, the small country may set higher tax rate than the large country.

\subsection{Tax competition versus tax coordination}

It remains to compare the welfare level reached in each country at the tax-competition and no-tax (efficient) outcomes. Consider, first, the case of cooperation between governments. Using (18) and (19), it is straightforward that the average utility level in the global economy is given by

$$
\bar{V}=\frac{1}{L}\left(l_{1} V_{1}+l_{2} V_{2}\right)=L-T\left(n_{1}, n_{2}\right) .
$$

As seen in the previous section, $T$ is minimized in the no-tax case. Hence, cooperation leads to the same outcome as zero tax rate in both countries.

Comparing utilities in two countries, we have

$$
V_{1}^{g}-V_{2}^{g}>0
$$

implying that the large country attains higher utility than does the small country under tax competition. Derivation of this inequality is given in Appendix C. Moreover, we can see that

$$
V_{2}^{g}-V_{2}^{m}>0 .
$$

Finally, as total output is lower under tax competition than under free competition, it must be that

$$
V_{1}^{g}-V_{1}^{m}<0 .
$$

Derivation of these inequalities is also given in Appendix C.

Consequently, we have:

Proposition 7 The large country's residents are always better off at the no-tax outcome, whereas the small country's residents prefer the tax-game outcome.

This shows that countries of different sizes have conflicting interests regarding tax competition since fiscal competition reduces international inequalities.

Finally, consider the effect of tax harmonization when the two countries set the same tax rate $\bar{t}$ on capital. Because (17) is reduced to (11), the distribution of firms is the same as that in the free market outcome. Therefore, there is no distortion in the sense that the net global output is maximized. However, we can see from (18) that the tax harmonization has some redistributional effect. Indeed, a resident in country $i$ gains (or loses) from tax harmonization by an amount equal to

$$
\Delta_{i}=\bar{t}\left(\frac{n_{i}^{m}}{l_{i}}-\frac{1}{f}\right) .
$$

It then follows from (23) and (24) that $\Delta_{1}<0$ and $\Delta_{2}>0$. This implies that, compared with the free market outcome, tax harmonization leads to income redistribution from the large to the small country. 


\section{Concluding remarks}

We have developed a new tax competition model that bears some resemblance with Ottaviano and van Ypersele (2005). In Ottaviano and van Ypersele, the large country has more firms per capita than does the small country both under tax competition and tax cooperation. By contrast, we have seen that the large country has less firms per capita in both situations. This is because we have a reverse home market effect, whereas the home market effect holds in Ottaviano and van Ypersele. It is hard to believe that such a difference in results is due to the sole existence of strategic interactions in our setting. Indeed, as shown by Head et al. (2002), strategic competition on the product market does not suffice to invalidate the home market effect. This suggests that, under imperfect competition, product-market and input-market analyses need not lead to similar conclusions.

Our approach allows us to uncover a new possible implication of fiscal competition. To see it, consider an economic environment in which not all workers take a job, the setting being otherwise similar to the one described above. Specifically, we assume that workers get the same level of unemployment benefit $b>0$ when unemployed. This implies that a worker supplies labor provided that her wage net of training costs is greater than or equal to $b$. Thisse and Zenou (2000) then show that the labor market equilibrium involves unemployment in country $i$ when $1<b+\beta / n_{i}$ holds, namely when the number of firms located in this country is sufficiently small. In this case, the most distant workers on the skill circle refrain from working, thus implying that each firm acts as a monopsony in the labor market. Because fiscal competition leads to a reduction in the number of firms installed in the small country, it is fairly straightforward to see that the small country may experience full employment in the no-tax case but unemployment at the taxation outcome. In other words, fiscal competition may also hurt the small country by generating unemployment.

Three possible extensions, at least, are worth mentioning. First, countries could use the tax proceeds to subsidize workers' training. In such a context, training costs would become lower and wages higher. However, lower training costs would reduce firms' market power and would make the corresponding country less attractive. The following question thus suggests itself: to which extent does one country subsidy its labor force more than the other, and get a better trained labor force, according to its size? Second, introducing capital accumulation with the aim of studying the relationship between economic growth and skill mismatch appears to be a fairly natural topic to investigate. Last, some empirical evidence suggests that several countries tax discriminate between local and foreign firms instead of applying the same tax rate as in this paper (Huizinga and Nicodème, 2005). It would be interesting to revisit our model when local governments may use such additional instruments. These topics are left for future investigation.

\section{References}

[1] Amiti, M. and C. A. Pissarides (2005) Trade and industrial location with heterogeneous labor, forthcoming in Journal of International Economics.

[2] Andersson F. and R. Forslid (2003) Tax competition and economic geography, Journal of Public Economic Theory 5, 279-303.

[3] Baldwin, R.E., R. Forslid, Ph. Martin, G.I.P. Ottaviano and F. Robert-Nicoud (2003) Economic Geography and Public Policy (Princeton, Princeton University Press). 
[4] Baldwin, R.E. and P. Krugman (2004) Agglomeration, integration and tax harmonization, European Economic Review 48, 1-23.

[5] Behrens, K. (2005) Market size and industry location: traded vs non-traded goods, Journal of Urban Economics 58, 24-44.

[6] Bucovetsky, S. (1991) Asymmetric tax competition, Journal of Urban Economics 30, 167-181.

[7] Devereux, M. P., R. Griffith and A. Klemm (2002) Corporate income tax reforms and international tax competition, Economic Policy 35,451-495.

[8] Dumais, G., G. Ellison, and E.-L. Glaeser (2002) Geographic concentration as a dynamic process, Review of Economics and Statistics 84, 193-204.

[9] Fujita, M., P. Krugman and A. J. Venables (1999) The spatial economy. Cities, regions and international trade (Cambridge,MA, MIT Press).

[10] Hamilton, J., J.-F. Thisse and Y. Zenou (2000) Wage competition with heterogeneous workers and firms, Journal of Labor Economics 18, 453-472.

[11] Haufler, A. and I. Wooton (1999) Country size and tax competition for foreign direct investment, Journal of Public Economics 71, 121-139.

[12] Head, K., T. Mayer and J. Ries (2002) On the pervasiveness of the home market effect, Economica 69, 371-390.

[13] Helsley, R. W. and W. C. Strange (1990) Matching and agglomeration economies in a system of cities, Regional Science and Urban Economics 20, 189-212.

[14] Huizinga, H. and G. Nicodème (2005) Foreign ownership and corporate income taxation: an empirical evaluation, forthcoming in European Economic Review.

[15] Kim, S. (1989) Labor specialization and the extent of the market, Journal of Political Economy $97,692-705$.

[16] Krugman, P.R. (1980) Scale economies, product differentiation, and the pattern of trade. American Economic Review 70, 950-959.

[17] Miyake, M. and M. Sass (2000) Recent trends in foreign direct investment, OECD Financial Market Trends 76, 23-41.

[18] Mooij, R.A. and S. Ederveen (2003) Taxation and foreign direct investment. A synthesis of empirical research, International Tax and Public Finance 10, 673-693.

[19] OECD (2003) OECD economic outlook 2003. Paris

[20] Ottaviano, G. I. P. and T. van Ypersele (2005) Market size and tax competition, Journal of International Economics 67, 25-46.

[21] Peralta, S. and T. van Ypersele (2005) Factor endowments and welfare levels in an asymmetric tax competition game, Journal of Urban Economics 57, 258-274.

[22] Rosenthal, S. and W. C. Strange (2004) Evidence on the nature and sources of agglomeration economics, in J.V. Henderson and J.-F. Thisse (eds.) Handbook of Regional and Urban Economics. Volume 4 (Amsterdam, Elsevier) 2119-2171. 
[23] Wilson, J. D. (1986) A theory of interregional tax competition, Journal of Urban Economics 19, 296-315.

[24] Wilson, J. D. (1991) Tax competition with interregional differences in factor endowments, Regional Science and Urban Economics 21, 423-452.

[25] Wilson, J. D. (1999) Theories of tax competition, National Tax Journal 52, 268-304.

[26] Thisse, J.-F. and Y. Zenou (2000) Skill mismatch and unemployment, Economics Letters 69, 415-420.

[27] Zodrow, G. R. and P. Mieszkowski (1986) Pigou, Tiebout, property taxation, and the underprovision of local public goods, Journal of Urban Economics 19, 356-370.

\section{Appendix A. Proof of Proposition 4.}

\section{Existence of a Nash equilibrium in the tax game.}

Hereafter, we show that the second-order condition is always satisfied at any point for which both the first-order conditions of the two countries $\left(d V_{1} / d t_{1}=0\right.$ and $\left.d V_{2} / d t_{2}=0\right)$ and the equalization of capital prices (19) hold. This shows that $t_{i}^{*}$ is the local best reply of government $i$ against $t_{j}^{*}$. As will be shown later, such a point exists and is unique, satisfying properties (23), (24) and (25).

From (19), it follows

$$
\begin{aligned}
\frac{d n_{i}}{d t_{i}} & =-\frac{1}{2 \beta}\left(\frac{l_{i}}{n_{i}^{3}}+\frac{l_{j}}{n_{j}^{3}}\right)^{-1}<0 \\
\frac{d^{2} n_{i}}{d t_{i}^{2}} & =6 \beta\left(\frac{d n_{i}}{d t_{i}}\right)^{2}\left(\frac{l_{j}}{n_{j}^{4}}-\frac{l_{i}}{n_{i}^{4}}\right) .
\end{aligned}
$$

The first-order condition for the maximization of $V_{i}$ with respect to $t_{i}$ is

$$
\frac{d V_{i}}{d t_{i}}=\frac{n_{i}}{l_{i}}-\frac{1}{f}+\left(\frac{5 \beta}{4 n_{i}^{2}}-\frac{2 \beta l_{i}}{f n_{i}^{3}}+\frac{t_{i}}{l_{i}}\right) \frac{d n_{i}}{d t_{i}}=0
$$

whereas the second-order derivative of $V_{i}$ with respect to $t_{i}$ yields

$$
\frac{d^{2} V_{i}}{d t_{i}^{2}}=\frac{2}{l_{i}} \frac{d n_{i}}{d t_{i}}+\frac{\beta}{n_{i}^{3}}\left(\frac{6 l_{i}}{f n_{i}}-\frac{5}{2}\right)\left(\frac{d n_{i}}{d t_{i}}\right)^{2}+\left(\frac{5 \beta}{4 n_{i}^{2}}-\frac{2 \beta l_{i}}{f n_{i}^{3}}+\frac{t_{i}}{l_{i}}\right) \frac{d^{2} n_{i}}{d t_{i}^{2}} .
$$

Using (A1) and (A2), $d^{2} V_{i} / d t_{i}^{2}$ may then be rewritten as follows:

$$
\begin{aligned}
\frac{d^{2} V_{i}}{d t_{i}^{2}} & =\left(-\frac{4 \beta l_{j}}{l_{i} n_{j}^{3}}-\frac{13 \beta}{2 n_{i}^{3}}+\frac{6 \beta l_{i}}{f n_{i}^{4}}\right)\left(\frac{d n_{i}}{d t_{i}}\right)^{2}+6 \beta\left(\frac{n_{i}}{l_{i}}-\frac{1}{f}\right)\left(\frac{l_{i}}{n_{i}^{4}}-\frac{l_{j}}{n_{j}^{4}}\right) \frac{d n_{i}}{d t_{i}} \\
& =\Phi_{i}\left(\frac{d n_{i}}{d t_{i}}\right)^{2}+6 \beta \Psi_{i} \frac{d n_{i}}{d t_{i}}
\end{aligned}
$$

where

$$
\begin{aligned}
\Phi_{i} & \equiv-\frac{4 \beta l_{j}}{l_{i} n_{j}^{3}}-\frac{13 \beta}{2 n_{i}^{3}}+\frac{6 \beta l_{i}}{f n_{i}^{4}} \\
\Psi_{i} & \equiv\left(\frac{n_{i}}{l_{i}}-\frac{1}{f}\right)\left(\frac{l_{i}}{n_{i}^{4}}-\frac{l_{j}}{n_{j}^{4}}\right) .
\end{aligned}
$$


When $i=1,(23)$ implies that

$$
\frac{n_{1}^{g}}{l_{1}}>\frac{n_{1}^{m}}{l_{1}}=\frac{1}{(\theta+\sqrt{\theta} \sqrt{1-\theta}) f}>\frac{4}{5 f}
$$

implying that

$$
\frac{5}{4}>\frac{l_{1}}{f n_{1}^{g}}
$$

so that

$$
\Phi_{1}<-\frac{4 \beta l_{2}}{l_{1}\left(n_{2}^{g}\right)^{3}}-\frac{13 \beta}{2\left(n_{1}^{g}\right)^{3}}+\frac{30 \beta}{4\left(n_{1}^{g}\right)^{3}} .
$$

Furthermore, $n_{1}^{m}>n_{2}^{m}$ and (23) imply that $n_{2}^{g}<n_{2}^{m}<n_{1}^{m}<n_{1}^{g}$. It then follows from (25) that

$$
\frac{l_{2}}{\left(n_{2}^{g}\right)^{3}}>\frac{l_{1}}{\left(n_{1}^{g}\right)^{3}}
$$

which in turn implies that

$$
\Phi_{1}<-\frac{4 \beta l_{1}}{l_{1}\left(n_{1}^{g}\right)^{3}}-\frac{13 \beta}{2\left(n_{1}^{g}\right)^{3}}+\frac{30 \beta}{4\left(n_{1}^{g}\right)^{3}}=-\frac{3 \beta}{\left(n_{1}^{g}\right)^{3}}<0 .
$$

Similarly, (25) yields

$$
\frac{l_{2}}{\left(n_{2}^{g}\right)^{4}}>\frac{l_{1}}{\left(n_{1}^{g}\right)^{4}}
$$

which, combined with (23), implies that

$$
\Psi_{1}>0
$$

For $i=2,(24)$ implies that

$$
1>\frac{l_{1}}{f n_{2}^{g}}
$$

Hence, we obtain

$$
\Phi_{2}<-\frac{4 \beta l_{1}}{l_{2}\left(n_{1}^{g}\right)^{3}}-\frac{13 \beta}{2\left(n_{2}^{g}\right)^{3}}+\frac{6 \beta}{\left(n_{2}^{g}\right)^{3}}=-\frac{4 \beta l_{1}}{l_{2}\left(n_{1}^{g}\right)^{3}}-\frac{\beta}{2\left(n_{2}^{g}\right)^{3}}<0 .
$$

Similarly, (A4) and (23) lead to

$$
\Psi_{2}>0 \text {. }
$$

From (A1), (A3) and (A5) to (A7), it then follows that

$$
\frac{d^{2} V_{i}}{d t_{i}^{2}}<0
$$

so that the second-order condition is satisfied for each $i=1,2$.

It remains to consider the following two cases. In the former, a country sets a tax rate sufficiently high for all the firms to be established in the other country. Clearly such a strategy is not optimal. In the latter, a country gives a sufficiently high subsidy to attract all firms. But then, the other country would reduce its tax rate.

2. Uniqueness of the Nash equilibrium in the tax game.

Substituting $n_{2}=N-n_{1}$ into (22), we see that both the left hand side (LHS) and the right hand side (RHS) of (22) depend on $n_{1}$. The LHS is negative and increases in $n_{1}$ in the interval 
$\left(0,8 l_{1} / 7 f\right)$, and is positive in $\left(8 l_{1} / 7 f, N\right]$. Moreover, it is readily verified that $\lim _{n_{1} \rightarrow 0} L H S=-\infty$ and $\left.L H S\right|_{n_{1}=8 l_{1} / 7 f}=0$. The RHS is positive in $\left[0, N-8 l_{2} / 7 f\right)$, and is negative and decreasing in $n_{1}$ in $\left(N-8 l_{2} / 7 f, N\right)$. We can also see that $\left.R H S\right|_{n_{1}=N-8 l_{2} / 7 f}=0$ and $\lim _{n_{1} \rightarrow N} R H S=-\infty$ (see Figure 2 for an illustration). Because $8 l_{1} / 7 f-\left[N-8 l_{2} / 7 f\right]=N / 7>0$, from Figure 2, we can easily see that there exists a unique point for which both the first-order conditions of the two countries $\left(d V_{1} / d t_{1}=0\right.$ and $\left.d V_{2} / d t_{2}=0\right)$ and the equalization of capital prices (19) hold. Hence, the proposition holds. Q.E.D.

\section{Appendix B. Proof of Proposition 5}

From (22), we have

$$
\left(\frac{n_{2}^{g} / l_{2}}{n_{1}^{g} / l_{1}}\right)^{2}=\frac{\left[7 / 8-l_{2} /\left(f n_{2}^{g}\right)\right] l_{1}}{\left[7 / 8-l_{1} /\left(f n_{1}^{g}\right)\right] l_{2}}
$$

From (12), we also have

$$
\left(\frac{n_{2}^{m} / l_{2}}{n_{1}^{m} / l_{1}}\right)^{2}=\frac{l_{1}}{l_{2}}
$$

Let us define $\gamma$ as follows:

$$
\gamma=\frac{7 / 8-l_{2} /\left(f n_{2}^{g}\right)}{7 / 8-l_{1} /\left(f n_{1}^{g}\right)}
$$

From Figure 2, we can see that $N-8 l_{2} /(7 f)<n_{1}^{g}<N<8 l_{1} /(7 f)$. This and $n_{2}=N-n_{1}$ imply that $7 / 8-l_{i} /\left(f n_{i}^{g}\right)<0$ for $i=1,2$, and that $\gamma>0$. (B1) and (B2) yield

$$
\frac{n_{2}^{g} / l_{2}}{n_{1}^{g} / l_{1}}=\gamma^{1 / 2} \frac{n_{2}^{m} / l_{2}}{n_{1}^{m} / l_{1}}=\left(\frac{\gamma l_{1}}{l_{2}}\right)^{1 / 2}
$$

Now assume that $\gamma \geq 1$. This implies that $7 / 8-l_{1} / f n_{1}^{g} \geq 7 / 8-l_{2} / f n_{2}^{g}$, which is reduced to $n_{1}^{g} / l_{1} \geq n_{2}^{g} / l_{2}$. However, since $\gamma \geq 1$ and $l_{1}>l_{2}$, (B3) yields $n_{2}^{g} / l_{2}>n_{1}^{g} / l_{1}$, which is a contradiction. Therefore, it must be true that $\gamma<1$. This means $7 / 8-l_{2} / f n_{2}^{g}>7 / 8-l_{1} / f n_{1}^{g}$, which gives

$$
\frac{n_{2}^{g}}{l_{2}}>\frac{n_{1}^{g}}{l_{1}} \text {. }
$$

Furthermore, from (B3), we obtain

$$
\frac{n_{2}^{m} / l_{2}}{n_{1}^{m} / l_{1}}>\frac{n_{2}^{g} / l_{2}}{n_{1}^{g} / l_{1}} .
$$

Note that $n_{1}+n_{2}=N$ implies

$$
\frac{n_{2} / l_{2}}{n_{1} / l_{1}}=\frac{N l_{1}}{l_{2} n_{1}}-\frac{l_{1}}{l_{2}} .
$$

Substituting this into (B5) gives

$$
n_{1}^{g}>n_{1}^{m}
$$

Similarly, we have

$$
\frac{n_{2} / l_{2}}{n_{1} / l_{1}}=\frac{1}{N l_{2} / l_{1} n_{2}-l_{2} / l_{1}}
$$

which and (B5) yield

$$
n_{2}^{m}>n_{2}^{g} \text {. }
$$


The proposition then follows from (B4), (B6) and (B7). Q.E.D.

\section{Appendix C. Derivation of Inequalities}

Comparing utilities in two countries, we have

$$
\begin{aligned}
V_{1}^{g}-V_{2}^{g} & =\frac{\beta}{4}\left(\frac{1}{n_{2}^{g}}-\frac{1}{n_{1}^{g}}\right)+\frac{n_{2}^{g}}{l_{2}}\left[\frac{\beta l_{2}}{\left(n_{2}^{g}\right)^{2}}-t_{2}\right]-\frac{n_{1}^{g}}{l_{1}}\left[\frac{\beta l_{1}}{\left(n_{1}^{g}\right)^{2}}-t_{1}\right] \\
& =\frac{\beta}{4}\left(\frac{1}{n_{2}^{g}}-\frac{1}{n_{1}^{g}}\right)+\frac{n_{2}^{g}}{l_{2}}\left[\frac{\beta l_{1}}{\left(n_{1}^{g}\right)^{2}}-t_{1}\right]-\frac{n_{1}^{g}}{l_{1}}\left[\frac{\beta l_{1}}{\left(n_{1}^{g}\right)^{2}}-t_{1}\right] \\
& =\frac{\beta}{4}\left(\frac{1}{n_{2}^{g}}-\frac{1}{n_{1}^{g}}\right)+\left[\frac{\beta l_{1}}{\left(n_{1}^{g}\right)^{2}}-t_{1}\right]\left(\frac{n_{2}^{g}}{l_{2}}-\frac{n_{1}^{g}}{l_{1}}\right)
\end{aligned}
$$

where the second equality follows from (17). Because $n_{1}^{m}>n_{2}^{m}$, (23) implies that $n_{2}^{g}<n_{2}^{m}<$ $n_{1}^{m}<n_{1}^{g}$ and, hence, $1 / n_{2}^{g}-1 / n_{1}^{g}>0$. Moreover, (20) and (24) imply that $\beta l_{1} /\left(n_{1}^{g}\right)^{2}-t_{1}>0$. Therefore, we have

$$
V_{1}^{g}-V_{2}^{g}>0 .
$$

Substituting (20) into (18), we also have

$$
V_{2}^{g}-V_{2}^{m}=\frac{5 \beta}{4 n_{2}^{m}}-\frac{\beta}{2 n_{2}^{g}}-\frac{3 \beta l_{2}}{4 f\left(n_{2}^{g}\right)^{2}}+\frac{\beta l_{2}}{f}\left[\frac{1}{\left(n_{2}^{g}\right)^{2}}-\frac{1}{\left(n_{2}^{m}\right)^{2}}\right]+\frac{2 \beta l_{1} l_{2}}{\left(n_{1}^{g}\right)^{3}}\left(\frac{n_{2}^{g}}{l_{2}}-\frac{1}{f}\right) .
$$

Since $(24)$ gives $l_{2} /\left(f n_{2}^{g}\right)<1$, we have

$$
\frac{5 \beta}{4 n_{2}^{m}}-\frac{\beta}{2 n_{2}^{g}}-\frac{3 \beta l_{2}}{4 f\left(n_{2}^{g}\right)^{2}}>\frac{5 \beta}{4}\left(\frac{1}{n_{2}^{m}}-\frac{1}{n_{2}^{g}}\right) .
$$

As a result, we obtain

$$
V_{2}^{g}-V_{2}^{m}>\left(\frac{1}{n_{2}^{m}}-\frac{1}{n_{2}^{g}}\right)\left[\frac{5 \beta}{4}-\frac{\beta l_{2}}{f}\left(\frac{1}{n_{2}^{g}}+\frac{1}{n_{2}^{m}}\right)\right]+\frac{2 \beta l_{1} l_{2}}{\left(n_{1}^{g}\right)^{3}}\left(\frac{n_{2}^{g}}{l_{2}}-\frac{1}{f}\right) .
$$

That $n_{2}^{m}>n_{2}^{g}$ and (24) imply that $V_{2}^{g}-V_{2}^{m}>0$ if $5 \beta / 4-\left(\beta l_{2} / f\right)\left(1 / n_{2}^{g}+1 / n_{2}^{m}\right)<0$. Since $n_{2}^{m}>n_{2}^{g}$ and (24) give that $1 / f<n_{2}^{g} / l_{2}<n_{2}^{m} / l_{2}$, it is readily verified that

$$
\frac{5 \beta}{4}-\frac{\beta l_{2}}{f}\left(\frac{1}{n_{2}^{g}}+\frac{1}{n_{2}^{m}}\right)<\frac{5 \beta}{4}-\frac{\beta l_{2}}{f} \frac{2}{n_{2}^{m}}<-\frac{3 \beta}{4}<0 .
$$

Hence, we have

$$
V_{2}^{g}-V_{2}^{m}>0
$$

Finally, as total output is lower under tax competition than under free competition, it must be that

$$
V_{1}^{g}-V_{1}^{m}<0 .
$$




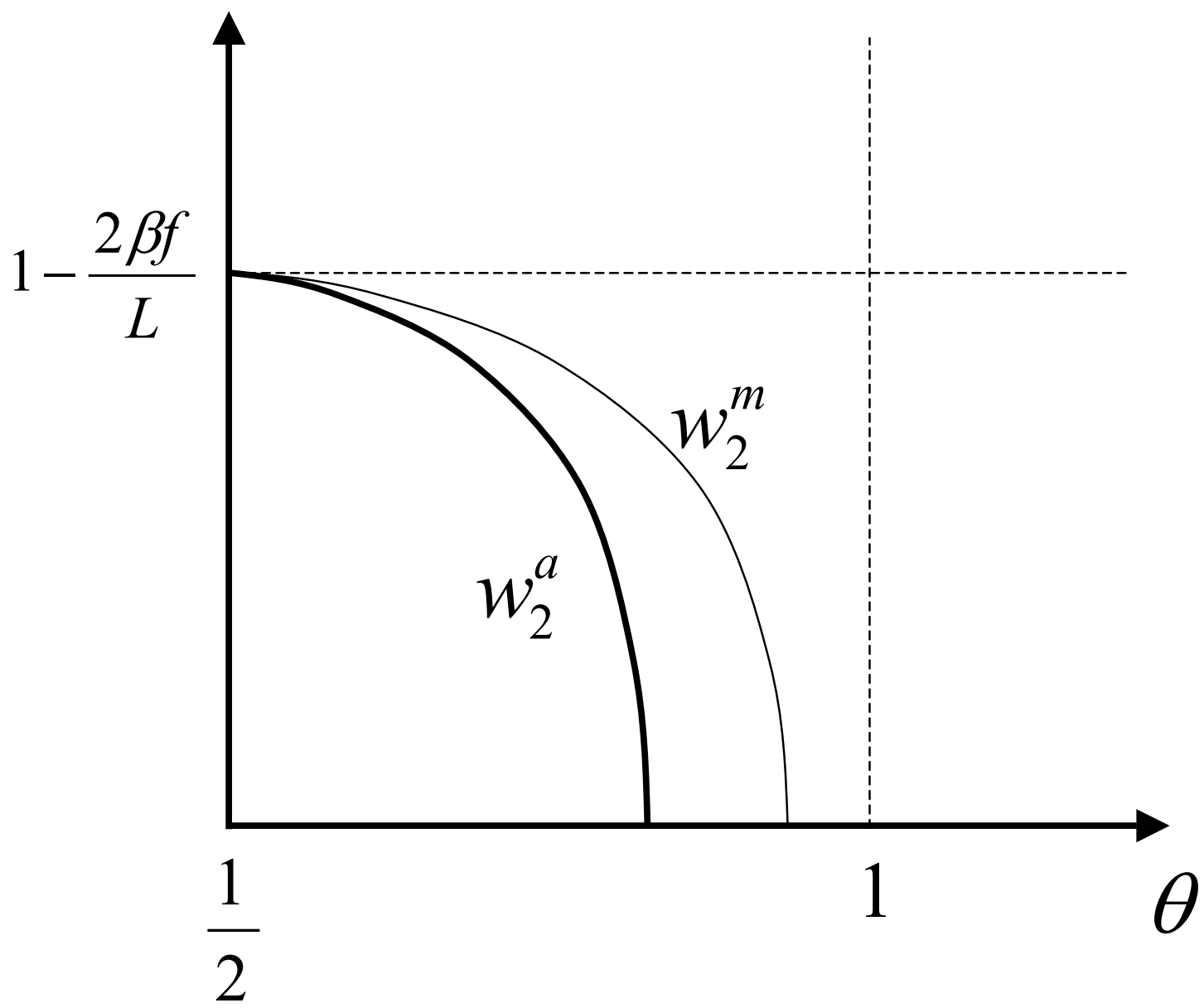

Figure 1: The effect of increases in $\theta$ on the wage rate in the small country

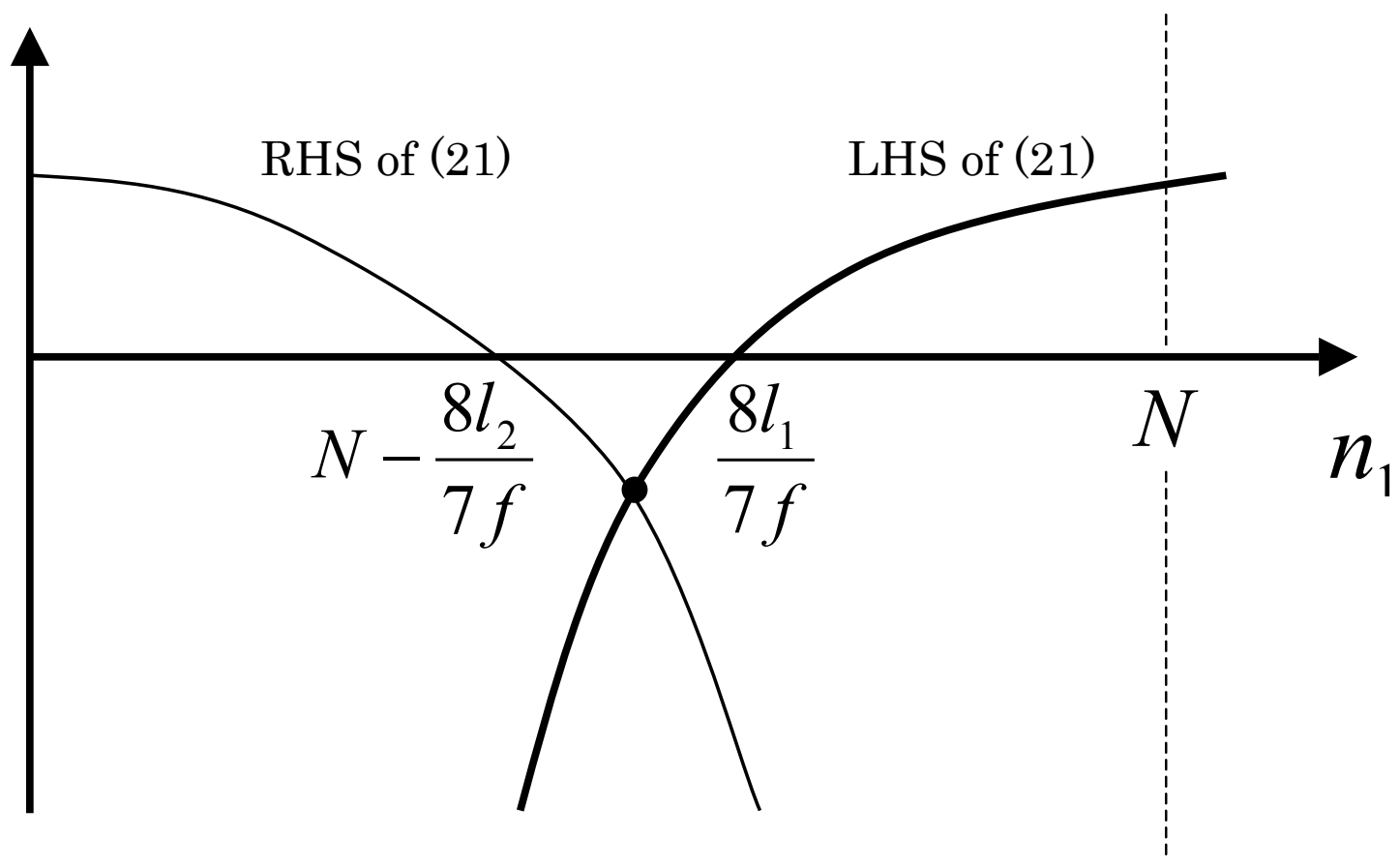

Figure 2: Nash equilibrium 
Département des Sciences Économiques de l'Université catholique de Louvain

Institut de Recherches Économiques et Sociales

Place Montesquieu, 3

1348 Louvain-la-Neuve, Belgique 